\title{
PONTOS DE CONVERGÊNCIA ENTRE O DIREITO INTERNACIONAL HUMANITÁRIO E O DIREITO INTERNACIONAL DOS REFUGIADOS: A PREVENÇÃO DO DESLOCAMENTO COMO MECANISMO DE SOBREVIVÊNCIA
}

Convergence points between International Humanitarian Law and International

Refugee Law: the prevention of displacement as a survival mechanism

Puntos de convergencia entre el Derecho Internacional Humanitario y el Derecho Internacional de Refugiados: la prevención del desplazamiento como mecanismo de supervivencia

Ádria Saviano Fabricio da Silva*
César Augusto S. da Silva**

Recebido em 22/03/2020. Aceito para publicação em 26/03/2020

Versão online publicada em 05/05/2020 (http://seer.ufrgs.br/paraonde)

\section{Resumo:}

Objetiva-se, com este trabalho, analisar a aproximação entre o Direito Internacional Humanitário e o Direito Internacional dos Refugiados por meio da investigação documental e bibliográfica, utilizando-se o método dedutivo e a abordagem qualitativa. Será possível caracterizar as principais nuances de ambos os direitos e identificar, assim, as diretrizes onde ocorrem as convergências da função protetiva do Direito Internacional Humanitário e do Direito Internacional dos Refugiados. Abordaremos tal aproximação por meio do estudo das normas e dos princípios fundadores de ambos os direitos através de três caminhos: a análise histórica, a análise teórica e a análise prática, utilizando, para tanto, o referencial teórico dos autores Antonio Augusto Cançado Trindade, Christophe Swinarsky e a doutrina amplamente divulgada pelo Comitê Internacional da Cruz Vermelha e pelo Alto Comissariado das Nações Unidas para Refugiados. Por fim faremos um breve estudo de caso da atuação da Federação Internacional da Cruz Vermelha na Venezuela.

Palavras-chave: Direito Internacional Humanitário. Direito Internacional dos Refugiados. ACNUR. CICV. Venezuela.

\footnotetext{
Abstract:

The objective of this paper is to analyse the approximation between International Humanitarian Law and International Refugee Law through documentary and bibliographic research, using the deductive method and the qualitative approach. It will be possible to characterize the main nuances of both rights and thus identify the guidelines where the protective function of international humanitarian law and international refugee law converge. We will approach this approach by studying the norms and founding principles of both rights through three paths: historical analysis, theoretical analysis and practical analysis, using
} 
the theoretical framework of the authors. Antonio Augusto Cançado Trindade, Christophe Swinarsky is the doctrine widely disseminated by the International Committee of the Red Cross and the United Nations High Commissioner for Refugees. Finally, we will make a brief case study of the work of the International Federation of the Red Cross in Venezuela.

Key-words: International Humanitarian Law. International Refugee Law. UNHCR. ICRC. Venezuela.

\begin{abstract}
Resumen:
El objetivo de este trabajo es analizar la aproximación entre el derecho internacional humanitario y el derecho internacional de los refugiados a través de la investigación documental y bibliográfica, utilizando el método deductivo con enfoque cualitativo. Será posible caracterizar los principales matices de ambos derechos y así identificar las pautas donde convergen la función protectora del derecho internacional humanitario y el derecho internacional de refugiados. Abordaremos este enfoque a través del estudio de las normas y principios fundacionales de ambos derechos a través de tres caminos: análisis histórico, análisis teórico y análisis práctico, utilizando el marco teórico de los autores. Antonio Augusto Cançado Trindade, Christophe Swinarsky es la doctrina ampliamente difundida por el Comité Internacional de la Cruz Roja y el Alto Comisionado de las Naciones Unidas para los Refugiados. Finalmente, haremos un breve estudio de caso sobre el trabajo de la Federación Internacional de la Cruz Roja en Venezuela.
\end{abstract}

Palabras-clave: Derecho Internacional Humanitario. Ley Internacional de Refugiados. ACNUR. CICR. Venezuela.

\title{
1. Introdução
}

Inicialmente cumpre salientar o marco teórico utilizado como ponto de partida deste estudo, qual seja o Prof. Dr. Antônio Augusto Cançado Trindade, que traça os pontos de convergência e delimita as relações que compõe o Sistema de Proteção Internacional da Pessoa Humana. Esse sistema não divisível, mas sim compartimentado e composto, portanto, por três subdivisões conhecidas como Direito Internacional dos Direitos Humanos, Direito Internacional Humanitário e Direito Internacional dos Refugiados, se comporta de modo que as três vertentes convergem para a mais completa proteção da pessoa humana em tempos de paz ou em tempos de guerra, onde quer que seja necessário (CANÇADO TRINDADE, 2006, p. 413).

Entretanto, o estudioso alicerceia a sua compartimentalização da Proteção Internacional da Pessoa Humana não só em uma divisão didática, mas sim na universalização da proposta de proteção fundamentada no que ele chama de consciência jurídica universal, a qual prevê o reconhecimento de valores compartilhados por todos os seres humanos e que, quando apropriados por tal consciência, passam a de fato conceder a eficácia necessária às medidas normativas que a compõem na prática e não só em tratativas teóricas e sem valor identificável, como antes visto.

Nunca é demais salientar que a concepção, análise e sistematização do Direito Internacional dos Direitos Humanos não estaria completa se, a par dos direitos e garantias, das normas substantivas e dos

ParaOnde!?, Porto Alegre, v.13, n.2, p.105-121, 2020.http://seer.ufrgs.br/paraonde Edição Especial - VII Seminário Internacional de Estudos Fronteriços 
mecanismos e procedimentos de proteção, não tivesse presentes igualmente os valores que Ihes são subjacentes. Estes valores são captados pela consciência humana, fonte material última desse novo corpus juris de proteção. Em meu entender, - permito-me reiterá-lo, é, em última análise, a consciência jurídica universal (cf. infra) que reconhece e dá expressão concreta aos direitos inerentes a todo ser humano, por conseguinte univdersais. (CANÇADO TRINDADE, 2006, p. 418)

A tal contexto une-se por óbvio os ideais propostos por Kant, com suas obrigações morais universais para com os estrangeiros em situação de vulnerabilidade e diante dos conflitos armados que, com o estabelecimento das Convenções de Genebra relativas aos conflitos armados e aos refugiados, se transformam em obrigações legais. Se em uma realidade ideal esperava-se que as obrigações morais universais fossem materializadas em princípios os quais fizessem parte da consciência moral universal, a sua concretude manifestada por meio das Convenções de Genebra nos leva à fixação de princípios legais que devem mais do que nunca ser protegidos.

Ao seguirmos este raciocínio, é notável relembrar que há décadas se discute a eficácia social da norma de direito internacional como fundamento de aplicabilidade do sistema internacional da pessoa humana aos casos concretos de violações de direitos humanos, tendo em vista a alegação, por parte de uma doutrina minoritária, de que seria impossível não só garantir a eficácia de normas genéricas adequadas a todos os povos - universalismo advindo dos imperativos categóricos de Kant e proposto por Cançado Trindade para a ordem internacional, bem como seria impensável constituí-las de forma justa a proteger indistintamente todos os seres humanos - ressalta-se que a posição majoritária é o universalismo, aplicado, inclusive, para justificar os instrumentos normativos de Direitos Humanos genéricos, os quais não fazem distinções e abarcam todos os seres humanos.

Ainda nesse sentido, se discute a primazia da ordem jurídica internacional sobre a ordem jurídica interna essencialmente no que tange à Proteção Internacional da Pessoa Humana, unindo, assim, os pensamentos de Hans Kelsen, em sua obra Teoria Geral do Direito e do Estado, na qual o filósofo admite a primazia da norma fundamental de Direito Internacional e ressalta o seu valor inigualável (KELSEN, 2000, p. 178), às formulas da lei universal e da humanidade de Kant, apesar de pertencerem a escolas diferentes e cada qual com a sua contribuição, ao entendermos que, respectivamente, há imperativos categóricos ou leis morais universais que alicerceiam toda a ordem jurídica internacional.

Aplicando ao Direito Internacional Humanitário seria o que mantém a integridade da ordem internacional e protege as pessoas das atrocidades dos conflitos armados internacionais e não-internacionais - e no que tange ao Direito Internacional dos Refugiados, "o direito de hospitalidade para o cidadão do mundo" e o valor intrínseco do ser humano em toda a sua dignidade, o qual deverá ser tratado como um fim em si mesmo e, portanto, protegido em qualquer circunstância, ambos conceitos jus-filosóficos Kantianos.

Deixando de lado todas as controvérsias sobre a própria natureza dessas regras imperativas e tomando o conceito de jus cogens em

ParaOnde!?, Porto Alegre, v.13, n.2, p.105-121, 2020.http://seer.ufrgs.br/paraonde Edição Especial - VII Seminário Internacional de Estudos Fronteriços 
uma acepção mais ampla que a que tem no direito internacional dos tratados (artigos 53 e 64 das Convenções de Viena sobre o Direito dos Tratados de 1969 e de 1986, respectivamente), é mister destacar - caráter imprescindível, para a sobrevivência da comunidade internacional, dos princípios do Direito Humanitário, pelo menos no sentido mínimo de "ordem pública internacional". (SWINARSKY, 1990, p. 33).

\section{A proteção internacional da pessoa humana aplicada ao DIH e ao DIR}

O refugiado é um indivíduo que flutua entre soberanias de países que não o seu originário, em busca de uma proteção já não oferecida pelo Estado o qual the conferiu a nacionalidade que carrega. É um ser abandonado pelo seu próprio Estado - nos casos de graves violações de Direitos Humanos, segundo a Declaração de Cartagena de 1984 ou de distúrbios da ordem pública, segundo a Carta Africana - ou perseguido por este - nos termos da Convenção de Genebra de 1951 relativa ao Estatuto dos Refugiados - pelas mais diversas razões, desde raça até religião. Em uma eterna busca pelo resguardo de seus direitos humanos, a ordem internacional é chamada a se manifestar, é solicitada a materializar em um instrumento internacional a garantia da proteção desses indivíduos.

Por outro lado, o civil que vive situação de conflito armado internacional ou não-internacional, o qual esteja ocorrendo dentro de seu país de origem ou em seu país de residência atual se vê abandonado pelo Estado - seja o seu de origem ou de residência - que não mais consegue lhe proteger através de obrigações estatais positivas ou mesmo negativas, pois este se encontra em calamidade devido ao conflito em si.

Em ambos os casos o Estado responsável pela proteção dos Direitos Humanos do indivíduo falha em garanti-los através da ação ou da omissão imperiosa, impetrando ou oportunizando graves violações de direitos humanos. O teórico Christophe Swinarsky faz unir os dois Direitos em uma categoria específica a qual ele determina mediante tal falha comissiva ou omissiva.

$\mathrm{Na}$ sua concepção, portanto, o Direito Internacional Humanitário e o Direito Internacional dos Refugiados devem ser analisados em conjunto e sempre em eterna comparação e convergência, pois ambos ocupam posição ímpar no ordenamento internacional de Direitos Humanos, compondo a última categoria das necessidades da pessoa humana, para aquelas situações em que pesam sobre os indivíduos ameaças particulares ou o impedimento de gozar da devida proteção do direito interno (SWINARSKY, 2001, p. 35).

O Direito Internacional dos Refugiados passa a ser, portanto, o novo patrono protetor do civil ou ex-combatente deslocado, antes abrangido pela proteção do Direito Internacional Humanitário que, buscando fugir do da realidade da guerra ou abandoná-la, se movimento para além das fronteiras conhecidas. Nas palavras de Francois Bugnion, em um de seus mais famosos artigos, o qual une claramente as duas vertentes, Refugees, Internally Displaced Persons, And International Humanitarian Law, de 2004: "War has

ParaOnde!?, Porto Alegre, v.13, n.2, p.105-121, 2020.http://seer.ufrgs.br/paraonde Edição Especial - VII Seminário Internacional de Estudos Fronteriços 
always been one of the main reasons people pull up and leave, the cause of the most massive displacements of population, of those that take place in the most tragic circumstances".

Na mesma direção está o pensamento de Cançado Trindade no que tange ao Direito Internacional dos Refugiados, realizando-se assim a devida diferenciação entre a situação de comum migração, na qual o Estado não deve interromper ou impedir a vontade de seu nacional de deixar o país (direito ao deslocamento, proveniente do artigo XIII, 2, da Declaração Universal de Direitos Humanos), e a de deslocamento forçado, no qual o Estado tem o dever de proteger as pessoas contra o exílio forçado, contra a diáspora obrigatória:

\begin{abstract}
El derecho a no ser forzado al exilio, em esta perspectiva, "implica el deber concomitante del Estado de proteger las personas contra el desplazamiento bajo coerción"; el objetivo fundamental del ACNUR es, pues, "assegurar que las personas em necesidad de protección reciban tal protección" (CANÇADO TRINDADE, RUIZ DE SANTIAGO, 2004, p. 10)

O direito de não ser forçado ao exílio, nessa perspectiva, "implica no dever concomitante do Estado de proteger as pessoas contra 0 deslocamento forçado"; o objetivo fundamental do ACNUR é, portanto, "assegurar que as pessoas com necessidade de proteção recebam tal proteção." (tradução livre)
\end{abstract}

Dessa forma, considerando que estamos vivenciando guerras que já duram mais do que a Segunda Guerra Mundial e a maior crise de deslocamento forçado desde aquela - segundo o relatório anual do ACNUR Global Trends Forced Displacement in 2017 -, justamente em decorrência de conflitos armados e de graves violações de direitos humanos, não há momento mais preciso do que este para trazer o tema à discussão. Precisamos mais do que nunca estudar as Convenções de Genebra.

Globally, the forcibly displaced population increased in 2017 by 2.9 million. By the end of the year, 68.5 million individuals were forcibly displaced worldwide as a result of persecution, conflict, or generalized violence. As a result, the world's forcibly displaced population remained yet again at a record high. (UNHCR, 2017, p. 2)

Globalmente, a população deslocada à força aumentou em 2,9 milhões em 2017. Até o final do ano, 68,5 milhões de pessoas foram deslocadas à força em todo o mundo resultado de perseguição, conflito ou violência generalizada. Como consequência, a população mundial deslocada à força permanece crescendo em nível recorde. (tradução livre)

\title{
2.1 Convergências históricas
}

Conforme o que já foi discutido ambos os órgãos - CICV e ACNUR foram criados partindo de uma necessidade de proteção de certo grupo vulnerável que não mais pode ser protegido pelo Estado que o engloba ou a este Estado a proteção deste grupo não mais interessa por ser ele mesmo o algoz ou por estar concentrando os seus esforços no conflito armado internacional ou não-internacional que se apresenta.

A criação do Comitê Internacional da Cruz Vermelha decorrente do

ParaOnde!?, Porto Alegre, v.13, n.2, p.105-121, 2020.http://seer.ufrgs.br/paraonde Edição Especial - VII Seminário Internacional de Estudos Fronteriços 
Movimento Internacional da Cruz Vermelha e do Crescente Vermelho, também chamado de "o Movimento" nasceu com a experiência do idealizador suíço Henry Dunant durante a Batalha de Solferino, no norte da Itália em 1859, devido à necessidade de a humanidade se organizar em tempos de Paz para prestar socorro em tempos de Guerra.

A falta de proteção que motivou a sua criação era proveniente da visualização das consequências da guerra e da sua dinâmica própria no sentido de que se vislumbravam combatentes feridos que não podiam se pôr longe do conflito ou mesmo receber atendimento médico caso se ferissem do lado errado.

Os médicos apenas estavam autorizados a tratar daqueles de seu país e exército e, mesmo que pudessem, não o fariam para o bem do inimigo. Por outro lado, os civis que se encontravam no meio do fogo cruzado acabavam sofrendo as consequências do uso indiscriminado de armas contra todos sem distinção dos objetivos militares, de modo que a morte do maior número de pessoas era o objetivo e o sofrimento era banalizado.

Não só com esse intuito, mas para evitar sofrimentos desnecessários em todos os âmbitos decorrentes de conflitos armados, os esforços do CICV modificaram a cultura de guerra e colocaram o ser humano no centro de perspectiva, de modo que para os conflitos modernos já temos construída a consciência de proteger os combatentes doentes e feridos, além de proteger os civis que em decorrência dos avanços militares venham a se defrontar com tal realidade.

Quanto aos instrumentos pensados para a proteção dos refugiados, temos a Convenção de Genebra de 1951 relativa ao Estatuto dos Refugiados, que nasce com 0 intuito de suprir necessariamente a grande crise de deslocamentos forçados que ocorria em decorrência da Segunda Guerra Mundial, de modo a concretizar os intentos realizados por meio instrumentos anteriores: Ajustes de 12 de maio de 1926 e de 30 de junho de 1928, Convenções de 28 de outubro de 1933 e de 10 de fevereiro de 1938 e Protocolo de 14 de setembro de 1939, e Constituição da Organização Internacional dos Refugiados.

Nessa Convenção nasce a definição clássica de refúgio - a qual nos demonstra o marco temporal em relação aos "fatos ocorridos antes de $1^{\circ}$ de janeiro de 1951" e espacial quanto à possibilidade de os Estados entenderem os refugiados apenas como os europeus ou utilizarem a interpretação extensiva abrangendo outras regiões do mundo. Nesse sentido, podemos identificar em sua finalidade e teor o tom genérico de proteção por vezes contaminado com as restrições impostas pelos Estados-Parte.

O próximo passo é histórico, quando verificamos esta ser aprimorada com o Protocolo sobre o Estatuto dos Refugiados de 1967, a fim de claramente se adaptar à nova realidade em que se encontrava o mundo após ter se observado os refugiados, como produtos das guerras e graves violações de direitos humanos que são, aparecerem com frequência e em grande quantidade em outros continentes e após o período da II Guerra Mundial, por

ParaOnde!?, Porto Alegre, v.13, n.2, p.105-121, 2020.http://seer.ufrgs.br/paraonde Edição Especial - VII Seminário Internacional de Estudos Fronteriços 
serem consequências de outros eventos como a descolonização africana e os conflitos internos latino-americanos consubstanciados em revoluções (guerras civis).

\subsection{Convergências teóricas}

As afinidades teóricas entre as duas vertentes são possíveis e comuns devido às suas origens e finalidades confluírem para a proteção da pessoa humana. Por representarem justamente as compartimentalizações que objetivam apenas especializarem-se a fim de se tornarem cada vez mais eficazes, é notável que sejam provenientes de um mesmo objetivo uno.

Estas, para fins do estudo aqui proposto, podem ser divididas em convergências principiológicas, produto da comparação entre os princípios fundadores do ACNUR e do CICV e em convergências normativas apontadas entre os diplomas internacionais que regem o DIR e o DIH.

\subsection{Convergências principiológicas}

O Comitê Internacional da Cruz Vermelha faz parte de um movimento humanitário global que, juntamente com as Sociedades e Federações Nacionais da Cruz Vermelha e do Crescente Vermelho de cada país, atuam com a missão de prevenir e aliviar o sofrimento humano onde quer que seja encontrado, particularmente em situações de conflitos armados e outras emergências, trabalhando em busca do desenvolvimento do respeito por todo o ser humano. A propagação das normas de Direito Internacional Humanitário e a ratificação das Convenções de Genebra de 1949 e de seus Protocolos Adicionais, bem como a internalização dos diplomas normativos internacionais de DIH também constam entre as finalidades do CICV.

Acerca dos princípios fundamentais que guiam as suas atitudes humanitárias globais perseguindo as missões institucionais propostas e onde quer que seja necessário atuar e de modo uno, independente e imparcial, podemos citar, segundo o Estatuto do Movimento Internacional da Cruz Vermelha e do Crescente Vermelho: a Imparcialidade - consistindo na nãodiscriminação e não seleção diante do sofrimento humano, sendo a assistência guiada pelo alívio da mais urgente causa de angústia -; a Neutralidade - diante do dever de não tomar parte ou escolher lados nas hostilidades -; a Independência - a fim de nunca se desviar dos fundamentos estabelecidos em razão de influências alheias e manter a sua autonomia; o Voluntariado - com o intuito de desvincular a sua atuação de qualquer ganho pessoal; a Unidade para que sejam reconhecidos os seus símbolos no mundo inteiro; a Universalidade - demonstrando que a responsabilidade do movimento é universal, para com toda a humanidade; e a Humanidade, elemento fundador do CICV:

The International Red Cross and Red Crescent Movement, born of a desire to bring assistance without discrimination to the wounded on the battlefield, endeavours, in its international and national capacity, to prevent and alleviate human suffering wherever it may be found. Its purpose is to protect life and health and to ensure respect for the

ParaOnde!?, Porto Alegre, v.13, n.2, p.105-121, 2020.http://seer.ufrgs.br/paraonde Edição Especial - VII Seminário Internacional de Estudos Fronteriços 
human being. It promotes mutual understanding, friendship, cooperation and lasting peace amongst all peoples.

O Movimento Internacional da Cruz Vermelha e do Crescente Vermelho, nascido do desejo de oferecer assistência sem discriminação aos feridos no campo de batalha, esforça-se, em sua capacidade internacional e nacional, por prevenir e aliviar 0 sofrimento humano onde quer que seja encontrado. Sua finalidade é proteger a vida e a saúde e garantir o respeito pelo ser humano. Promove a compreensão mútua, a amizade, a cooperação e a paz duradoura entre todos os povos. (tradução livre)

Ao se resumir todos estes ideais e princípios, teríamos os lemas "inter arma caritas", significando a caridade, filantropia e a própria atuação humanitária entre armas, diretamente atuando no conflito armado e "per humanitatem ad pacem", o qual significaria, basicamente, com a humanidade em busca da paz, os quais expressariam a atuação do CICV.

Já acerca dos princípios fundadores do Alto Comissariado das Nações Unidas para Refugiados, segundo o seu Estatuto, verificamos que, assim como realizado pelo $\mathrm{CICV}$, patrono do $\mathrm{DIH}$, o ACNUR também objetiva propagar as normas de DIR e incentivar a ratificação da Convenção de Genebra de 1951 e de seu Protocolo Adicional de 1967, assim como a apropriação interna na legislação nacional de cada país. A cooperação com as demais organizações protetoras de causas humanitárias que se relacionem com a questão dos refugiados também é motivo de convergência. Em relação aos seus objetivos e natureza, o ACNUR se assemelha à CICV, como já mencionado, por sua finalidade de proteção e por sua natureza humanitária, segundo o ponto 01, do capítulo 01 - General Provisions -, do Estatuto do ACNUR, relacionando em seu teor os princípios da acolhida humanitária e da integração local:

The United Nations High Commissioner for Refugees, acting under the authority of the General Assembly, shall assume the function of providing international protection, under the auspices of the United Nations, to refugees who fall within the scope of the present Statute and of seeking permanente solutions for the problem of refugees by assisting Governments and, subject to the approval of the Governments concerned, private organizations to facilitate the voluntary repatriation of such refugees, or their assimilation within new national communities.

O Alto Comissariado das Nações Unidas para os Refugiados, agindo sob a autoridade da Assembleia Geral, assumirá a função de fornecer proteção internacional, sob os auspícios das Nações Unidas, aos refugiados que se enquadrem no escopo do presente Estatuto e de buscar soluções permanentes para o problema dos refugiados, auxiliando os governos e, sujeito à aprovação dos governos interessados, organizações privadas para facilitar o repatriamento voluntário de tais refugiados ou sua assimilação dentro de novas comunidades nacionais. (tradução livre)

\subsection{Convergências normativas}

Considerando as finalidades das normas que compõe o Sistema de Proteção da Pessoa Humana e a abrangência global da consciência jurídica universal, as normas convergem no sentido de objetivarem proteger as vítimas

ParaOnde!?, Porto Alegre, v.13, n.2, p.105-121, 2020.http://seer.ufrgs.br/paraonde Edição Especial - VII Seminário Internacional de Estudos Fronteriços 
dos conflitos armados que podem ou não estarem em transferência ou deslocamento interno ou externo. O âmbito de proteção e o reconhecimento aplicados para os civis em deslocamento são os mesmos, sejam esses deslocamentos para além das fronteiras internacionais ou uma mera evacuação prevista para a proteção dos civis mediante a IV Convenção de Genebra.

Os refugiados são pessoas que atravessaram uma fronteira internacional e correm risco de ser ou são vítimas de perseguição no seu país de origem. As pessoas podem se tornar refugiadas por diferentes motivos, incluindo aqueles relacionados com conflitos armados. Em geral, o DIH protege os refugiados da mesma forma que protege outros civis afetados pelos conflitos armados. Algumas dessas normas são adaptadas para os refugiados para refletir a sua vulnerabilidade particular na ausência de proteção proporcionada pelo seu Estado de nacionalidade. (...) Segundo o DIH, como civis, as pessoas estão protegidas contra e durante os deslocamentos, desde que não participem diretamente das hostilidades. (ICRC, 2016)

É interessante percebermos, portanto, como alguns dos mais importantes fundamentos do Direito Internacional dos Refugiados acaba por ter como o seu primeiro protetor o Comitê Internacional da Cruz Vermelha. Se o deslocamento forçado é proveniente de uma série de causas, quando a causa principal é um conflito armado internacional ou não-internacional, a primeira medida a ser tomada será a de transferência ou evacuação de civis, prevista no artigo 49, da IV Convenção de Genebra relativa aos Conflitos Armados.

Quanto às respostas ao deslocamento forçado, o CICV busca de diversas formas prevenir o deslocamento forçado e as suas consequências realizando ações de modo a preparar as comunidades em risco de deslocamento através de algumas de suas diretrizes como: fortalecer os sistemas de aviso antecipado; realizar a correta preparação para fugir, fundamentada em identificar rotas de escape seguras, obter informações acerca do paradeiro dos familiares, garantir a proteção dos documentos pessoais; além do diálogo com grupos armados não estatais e autoridades estatais sobre o dever de prevenir o deslocamento e sobre as consequências humanitárias do não cumprimento das normas humanitárias.

Utilizando esse procedimento, o CICV busca realizar um deslocamento planejado de modo mais seguro possível, antecipando informações sobre a sua ocorrência e garantindo a saúde, as necessidades sanitárias e fortalecendo a resiliência das pessoas para se prepararem para a partida, deslocando-as dentro das fronteiras do próprio país e assegurando-se da manutenção da unidade familiar - princípio constante dentre as regras de Direito Internacional Humanitário:

Maintenance of family unity. The duty to avoid, as far as possible, separation of members of a family is provided for in the Fourth Geneva Convention in the context of transfers or evacuations of civilians by an occupying power. The commentary to Rule 131 on the treatment of displaced persons includes practice requiring respect for family unity in general terms not limited to displacement. (DOSWALDBECK, HENCKAERTS, 2005, p. 380)

Manutenção da unidade familiar. O dever de evitar, na medida do

ParaOnde!?, Porto Alegre, v.13, n.2, p.105-121, 2020.http://seer.ufrgs.br/paraonde Edição Especial - VII Seminário Internacional de Estudos Fronteriços 
possível, a separação de membros de uma família está previsto na Quarta Convenção de Genebra no contexto de transferências ou evacuações de civis por uma potência de ocupação. O comentário ao artigo 131 do Regimento sobre o tratamento de pessoas deslocadas inclui uma prática que exige respeito pela unidade familiar em termos gerais não limitados ao deslocamento. (tradução livre)

Dentre tais objetivos, "interagir com outros atores, com base nos seus mandatos e conhecimento, de modo a encontrar soluções para casos específicos ou problemas que afetam as comunidades deslocadas" (ICRC, 2016) caracteriza o dever de cooperação em prol da proteção da pessoa humana, sedimentada no seu compartilhamento de princípios, entretanto, pouco explorada na prática, apesar da busca da CICV e do ACNUR em atuar em complementação aos esforços um do outro, considerando estar e permanecer onde outro atores humanitários não têm acesso ou tardarão a têlo. (ICRC, 2008)

\subsection{Convergências práticas: atuação do CICV e do ACNUR}

Ambos os direitos convergem na prática no momento em que os denominados civis (protegidos pela IV Convenção de Genebra de 1949), considerados aqueles que não participam do conflito ou deixaram de participar por não mais terem condições de fazê-lo, devem decidir por permanecer em casa e se arriscar a morrer em um ataque ou fugir e perder tudo o que têm. Ao decidirem pelo deslocamento forçado, os antes considerados civis se tornam deslocados internos, caso permaneçam dentro das fronteiras, ou refugiados, caso atravessem as fronteiras.

O CICV e o ACNUR são os patronos do Direito Internacional Humanitário e do Direito Internacional dos Refugiados respectivamente. As convergências se demonstram desde as finalidades para as quais os órgãos foram criados quanto ao seu caráter de proteção até as suas missões institucionais, passando pela cooperação organizacional e tendo em vista a sua tutela dos direitos humanos de quem necessite ou a estes órgãos recorra, o encontro nas grandes zonas de conflito armado internacional e não internacional é comum.

Entretanto, o CICV, por sua independência e apesar de suas semelhanças com o ACNUR no que tange à certa resistência a mudanças de paradigmas e à flexibilidade própria de alguns procedimentos, acaba se destacando por ter estabelecido desde o início de suas atividades uma doutrina clara e diretrizes e treinamento sistemático próprios (FORSYTHE, 2005, p. 73). Já em termos de comparação quanto à atuação sem os recursos das Nações Unidas destinados ao ACNUR, e apesar destes, o CICV se mantém como uma organização tão competente quanto aquele em aliviar o sofrimento humano:

If we look at ICRC relief after the cold war, we find an organization always present to provide relief in conflicts, and arguably as good as or better than the other major relief agencies such as UNHCR, UNICEF, WFP and Oxfam. (FORSYTHE, 2005, p. 85)

Se olharmos para a ajuda do CICV depois da Guerra Fria, encontramos uma organização sempre presente para fornecer ajuda

ParaOnde!?, Porto Alegre, v.13, n.2, p.105-121, 2020.http://seer.ufrgs.br/paraonde Edição Especial - VII Seminário Internacional de Estudos Fronteriços 
nos conflitos e, possivelmente, tão boa ou melhor do que as outras grandes agências de assistência, como o ACNUR, UNICEF, WFP e Oxfam. (tradução livre)

Comparações à parte, ambos os órgão são considerados instituições as quais tomam iniciativas próprias e autônomas que independem da prévia aprovação dos Estados, mas que, entretanto, dependem destes para obter a eficácia nas ações que promovem; de modo que podemos concluir que sem a cooperação internacional, seria impossível 0 impacto que hoje estas instituições geram em termos de contribuições humanitárias benéficas para a proteção do ser humano.

\title{
3. O deslocamento como mecanismo de sobrevivência
}

Tais organizações tratam e protegem todos os seres humanos, aos quais tenham sido compulsoriamente imputadas duas condições específicas, quais sejam ser civil em meio a conflito armado internacional ou não internacional, desde que não esteja tomando parte no conflito, por quaisquer razões que o apartem da situação, e a de deslocamento forçado. Para fugir do conflito armado o mecanismo de sobrevivência mais conhecido é o deslocamento. Chamado de forçado pois sua causa não é a autonomia privada dos indivíduos, mas sim uma necessidade que perpassa suas liberdades.

\begin{abstract}
Com frequência, o deslocamento é um mecanismo de sobrevivência, quando fugir é o único recurso que as pessoas têm para evitar um perigo ou uma privação iminente. No entanto, o deslocamento também tende a fazer com que as pessoas se tornem mais vulneráveis, muitas vezes piorando exacerbando as dificuldades que já enfrentam como consequência do conflito armado ou da violência à sua volta. (ICRC, 2008)
\end{abstract}

Há muito tempo desloca-se forçadamente no mundo, entretanto, apenas com a grandiosidade dos impactos ocorridos com a Segunda Guerra Mundial, foram vislumbrados as consequências e o grau de vulnerabilidade do contingente que se desloca. Foi possível assim enxergar em âmbito global como funcionavam os grandes deslocamentos e como isso afetava individualmente a dignidade humana de cada pessoa por ocasião da perda do direito de permanecer na sua terra natal e perto de tudo que se conhecia, inclusive da convivência com o grupo social que se relacionava; demonstrando assim, a perda da identidade construída por meio das raízes constituídas no local e a humilhação da expulsão.

To be rooted is perhaps the most important and least recognized need of the human soul. It is one of the hardest to define. A human being has roots by virtue of his real, active and natural participation in the life of a Community which preserves in living shape certain particular treasures of the past and certain particular expectations for the future. (WEIL, 1949, p. 40).

Estar enraizado é talvez a necessidade mais importante e menos reconhecida da alma humana. É uma das mais difíceis de definir. Um ser humano tem raízes em virtude de sua participação real, ativa e natural na vida de uma comunidade que preserva em forma de vida certos tesouros particulares do passado e certas expectativas

ParaOnde!?, Porto Alegre, v.13, n.2, p.105-121, 2020.http://seer.ufrgs.br/paraonde Edição Especial - VII Seminário Internacional de Estudos Fronteriços 


\title{
particulares para o futuro. (tradução livre)
}

É essencial ressaltarmos a importância do cumprimento das normas de Direito Internacional Humanitário (mais especificamente do Direito de Genebra) para a prevenção do deslocamento forçado decorrente de conflitos armados, fato este que vem sendo reiteradamente negligenciado pelos Estados.

\begin{abstract}
Sempre que possível, também buscamos prevenir que 0 deslocamento ocorra em primeiro lugar ao trabalhar algumas das suas causas. Em conflitos armados, assegurar que todas as partes tanto os Estados e atores não estatais - a cumprirem com o Direito Internacional Humanitário (DIH), em particular as normas que protegem os civis contra os efeitos das hostilidades, pode ajudar a reduzir o deslocamento. (...) (ICRC, 2008)
\end{abstract}

Por outro lado, quanto aos deslocamentos provenientes de crises socioeconômicas, desastres naturais, outras situações de violência e violação maciça de direitos humanos, verificamos a atuação de outros órgãos membros do Movimento Internacional da Cruz Vermelha e do Crescente Vermelho com o Direito Internacional dos Refugiados, caso em que veremos a seguir.

\section{A federação internacional da Cruz Vermelha (FICV) e o Comitê Internacional da Cruz Vermelha (CICV) na Venezuela}

Considerando as definições de refúgio presentes na Convenção de Genebra de 1951 relativa ao Estatuto dos Refugiados e na Declaração de Cartagena de 1984, percebemos que, fundamentalmente, a primeira se destaca por ser um diploma global que conecta a condição de refugiado à causa de deslocar-se forçadamente por motivos de perseguição, os quais se relacionam diretamente a Conflitos Armados Internacionais e NãoInternacionais, caso em que atua o Comitê Internacional da Cruz Vermelha (CICV). Por outro lado, a segunda definição já trata de outras formas de violência, as quais igualmente violam os direitos humanos, causando o risco de morte, mas que não decorrem de violências obrigatoriamente e diretamente físicas, como é mais comum nos conflitos armados e demais situações de perseguição religiosa e étnica, dentre outras.

Tais violências se dão em âmbitos como: a escassez de alimentos e remédios para atender minimamente a população, gerando fome e a propagação de doenças; hiperinflação que impeça a população de comprar provisões; a falência das instituições democráticas como as forças de segurança, as forças armadas, o sistema de saúde e de educação gerando a violação de mais uma série de direitos básicos e a desestabilização geral do país inclusive e especificamente no que tange à violência generalizada, dentre outras consequências. Isto ocorre porque barreiras a serviços básicos além de insuflarem o deslocamento, sendo por vezes, a sua principal causa, transformam-no em crises humanitárias de grande porte. No caso venezuelano, a magnitude da crise tem destruído qualquer possibilidade de garantir a saúde e a própria sobrevivência da população.

A Federação Internacional das Sociedades da Cruz Vermelha e do Crescente Vermelho é o órgão responsável dentro da lógica do Movimento por

ParaOnde!?, Porto Alegre, v.13, n.2, p.105-121, 2020.http://seer.ufrgs.br/paraonde Edição Especial - VII Seminário Internacional de Estudos Fronteriços 
intervir nas referidas crises socioeconômicas e/ou humanitárias, as quais não decorrem de conflitos armados, mas sim de outros fatores que geram calamidades, como desestabilizações políticas, econômicas e sociais e desastres naturais, a fim de apoiar a Sociedade Nacional que de apoio necessite, conforme 0 art. 5을 parágrafo 1 - A, "d" e "e" da International Federation of Red Cross and Red Crescent Socities's Constitution e o art. 6을 parágrafo 4, "a" e "e" dos Statutes Of The International Red Cross And Red Crescent Movement.

Nesse sentido, legitimada para tal, a FICV é o órgão que faz cumprir ao direito internacional dos refugiados um local de destaque dentro das causas humanitárias lato sensu: "The IFRC's mission is to improve the situation of the most vulnerable, coordinating emergency international assistance to people affected by natural and man-made disasters, including the forcibly displaced, and in health crises" (UNHCR).

No caso venezuelano a FICV custou muito a conseguir autorização para agir por uma série de motivos, os quais analisaremos a seguir. Inicialmente há a resistência em razão da negação da crise humanitária por parte do governo venezuelano. Receber o Movimento na Venezuela restaria em admitir a crise socioeconômica humanitária de larga escala que impera no país, razão pela qual o presidente Nicolás Maduro evitava o assunto, sempre alinhando as dificuldades pelas quais estava passando a Venezuela a embargos econômicos provenientes da tensa relação com os maiores países capitalistas do globo, em especial com os Estados Unidos.

Ademais, interesses políticos teriam sido postos como condição para a entrada da Organização Humanitária e não foram aceitos em respeito ao princípio da Neutralidade, o qual pode ser definido, segundo os Statutes Of The International Red Cross And Red Crescent Movement: Neutrality, In order to continue to enjoy the confidence of all, the Movement may not take sides in hostilities or engage at any time in controversies of a political, racial, religious or ideological nature ${ }^{1}$.

A Imparcialidade também se mostra um princípio extremamente importante nesse caso, tendo em vista que prescinde do próprio ideal de fundação do Movimento, tornando-o independente e, portanto, livre de qualquer juízo de valor no que tange a demandas políticas e outros fatores que não sejam a ajuda humanitária.

O trabalho conjunto do ACNUR e da FICV no que tange a desastres naturais ou decorrentes de ações humanas, causando as crises humanitárias com os amplos impactos observados, se apresenta como uma das principais convergências entre o Direito Internacional dos Refugiados e o Direito internacional Humanitário: "the IFRC and UNHCR have been working together for more than 50 years" (UNHCR). Dentre os acordos fixados, memorandos de entendimento como o de 2002 permitiram que funcionários do ACNUR e suas

\footnotetext{
${ }^{1}$ Estatutos do Movimento Internacional da Cruz Vermelha e do Crescente Vermelho: Neutralidade, para continuar a gozar da confiança de todos, o Movimento não pode tomar partido nas hostilidades ou envolver-se a qualquer momento em controvérsias de natureza política, racial, religiosa ou ideológica.
}

ParaOnde!?, Porto Alegre, v.13, n.2, p.105-121, 2020.http://seer.ufrgs.br/paraonde Edição Especial - VII Seminário Internacional de Estudos Fronteriços 
famílias recebessem treinamento de primeiros socorros para eventual necessidade na prática (IFRC, 2002).

A presença do Comitê Internacional da Cruz Vermelha na Venezuela também gera uma série de cooperações mútuas para o alívio do sofrimento humano e a atenuação da crise humanitária que lá se instalou. Presente desde 1966 no país, o CICV decidiu por fortalecer a relação com a Cruz Vermelha Venezuelana, de modo a melhor lidar com alguns dos principais desafios encontrados, os quais seriam a saúde, a violência generalizada, o reestabelecimento de laços familiares e as violações maciças de direitos humanos na fronteira com a Colômbia.

Sobre o reestabelecimento de laços familiares podemos dizer que é o principal ponto de suporte por meio do qual o Movimento se insere na vertente do Direito Internacional dos Refugiados, considerando que o CICV possui um sistema próprio de busca para a Reunião Familiar, princípio basilar desta vertente.

Um grande exemplo deste compromisso é retratado nas recentes atividades desenvolvidas pelo CICV em parceria com a Cruz Vermelha Venezuelana objetivando a proteção deste princípio, ocasiões em que, juntamente com a referida Sociedade Nacional, o CICV trabalha enviando mensagens e auxiliando na busca por familiares desaparecidos com 0 programa restaurando laços familiares (Restoring Family Links - RFL):

\begin{abstract}
There is a direct link between being together as a family and human dignity. Any time people are separated from their loved ones, or have no news of them as a result of armed conflict, situations of violence, natural disasters or migration, the International Red Cross and Red Crescent Movement is there to restore contact between family members. (ICRC, 2018)

Existe uma conexão entre a unidade familiar e a dignidade humana. Sempre que as pessoas são separadas de seus entes queridos ou não têm notícias delas como resultado de conflitos armados, situações de violência, desastres naturais ou migração, o Movimento Internacional da Cruz Vermelha e do Crescente Vermelho estará lá para restabelecer o contato entre os membros da família. (tradução nossa)
\end{abstract}

\title{
5. Considerações finais
}

Trazendo à baila a discussão aqui apresentada, munimo-nos do objetivo de investigar e por consequência demonstrar as convergências entre o Direito Internacional dos Refugiados e o Direito Internacional Humanitário através do estudo das atuações de seus respectivos patronos, quais sejam o Alto Comissariado das Nações Unidas para Refugiados e o Comitê Internacional da Cruz Vermelha.

A fim de analisar detidamente cada particularidade das convergências, foram divididos os panoramas entre: convergências históricas; convergências teóricas - subdivididas em principiológicas e normativas - e convergências práticas. Além disso, buscou-se trazer a este estudo a fundamentação histórica da criação dos diplomas normativos que hoje alicerceiam ambas as vertentes.

ParaOnde!?, Porto Alegre, v.13, n.2, p.105-121, 2020.http://seer.ufrgs.br/paraonde Edição Especial - VII Seminário Internacional de Estudos Fronteriços 
Conclui-se, assim, que a compartimentalização da Proteção Internacional da Pessoa Humana foi realizada historicamente de modo natural, tendo em vista que o Direito quando restrito à um grupo social ou a uma certa condição ou estado do ser humano nasce para cumprir com determinada necessidade apresentada pela própria humanidade, fazendo jus à proteção específica, pois o rol de "direitos das gentes" previstos para todos indistintamente não é suficiente para abarcar aquela situação (VATTEL, 2004).

Em decorrência desta natural cisão, seguem as demais consequências teóricas - normativas (nascendo a seu próprio tempo e respeitando o seu desenvolvimento histórico, o conjunto de legislação internacional de cada vertente) e principiológicas (pensados os fundamentos mais importantes de cada Direito a serem resguardados pelos órgão responsáveis por propagá-los) - e práticas, caracterizadas pela cooperação entre as organizações protetoras humanitárias, seja qual for a sua natureza (independente, autônoma ou vinculada), objetivando, tanto a atuação em conjunto para lidar com as consequências dos desastres, graves violações de direitos humanos e conflitos armados internacionais e não internacionais, como o foco na propagação dos princípios humanitários e na disseminação do dever do cumprimento das normas humanitárias.

Por fim, é imperioso salientar a posição majoritária dos grandes teóricos e líderes atuantes do Direito Internacional Humanitário e do Direito Internacional dos Refugiados aqui citados quanto à necessidade urgente de se fazer cumprir as normas de DIH, quais sejam as Convenções de Genebra de 1949 e seus Protocolos Adicionais, para que não seja preciso se recorrer às normas de Direito Internacional dos Refugiados; atuar, assim, na prevenção do deslocamento forçado como mecanismo de sobrevivência em meio aos conflitos armados.

\section{Referências}

CANÇADO TRINDADE, Antônio Augusto. Desafios e conquistas do direito internacional dos direitos humanos no início do século XXI. XXXIII In Curso de Direito Internacional Organizado pela Comissão Jurídica Interamericana da OEA. Rio de Janeiro, 2006.

CANÇADO TRINDADE, Antônio Augusto. A Proteção dos Vulneráveis como Legado da II Conferência Mundial de Direitos Humanos (1993-2013). In III Curso Brasileiro Interdisciplinar de Direitos Humanos. Fortaleza: IBDH IIDH - SLADI, 2014.

CANÇADO TRINDADE, Antônio Augusto. RUIZ DE SANTIAGO, Jaime. La nueva dimensión de las necessidades de protección del ser humano em el inicio del siglo XXI. 3a Ed. San José, Costa Rica: ACNUR, 2004, p. 42, apud. UNHCR, Statement by the United Nations High Comissioner for Refugees (Mrs. Sadako Ogata) to the XLIX Session of the Comissiono of Human Rights. Ginebra: 1993, p. 10.

Convenção de Genebra IV. Adotada a 12 de agosto de 1949 pela Conferência

ParaOnde!?, Porto Alegre, v.13, n.2, p.105-121, 2020.http://seer.ufrgs.br/paraonde Edição Especial - VII Seminário Internacional de Estudos Fronteriços 
Diplomática destinada a Elaborar as Convenções Internacionais para a Proteção das Vítimas da Guerra. Entrada em vigor na ordem internacional: 21 de outubro de 1950. Biblioteca Virtual de Direitos Humanos - USP.

DOSWALD-BECK, Louise. HENCKAERTS, Jean-Marie. Customary International Humanitarian Law. Volume I: Rules. International Committee of The Red Cross. Cambridge: Cambridge University Press, 2005.

FORSYTHE, David P. The Humanitarians: The International Committee of the Red Cross. Cambridge: Cambridge University Press, 2005, chapter 8.

ICRC. Statutes of the international red cross and red crescent movement. Adopted by the 25th International Conference of the Red Cross at Geneva in 1986, amended in 1995 and 2006.

ICRC. Deslocados internos. 2008. Disponível na Internet. https://www.icrc.org/pt/document/deslocados-internos Acesso em: 25 mai 2019.

ICRC. Perguntas Frequentes sobre DIH. Disponível na Internet. https://www.icrc.org/pt/document/perguntas-frequentes-sobre-dih Acesso em: 26 mai 2019. Publicado em 19 out 2016.

ICRC. ICRC Regional Delegation For Venezuela and Caricom States. janabr 2018.

IFRC. Constitution. Revised and adopted by the 16th Session of the General Assembly Geneva (Switzerland), 20-22 November 2007.

IFRC. Red Cross Red Crescent and UNHCR collaborate on first aid. 2002. Disponível na Internet. https://www.ifrc.org/ar/news-and-media/pressreleases/europe/switzerland/red-cross-red-crescent-and-unhcr-collaborate-onfirst-aid/ Acesso em: 8 ago 2019.

KELSEN, Hans. Teoria geral do direito e do Estado. Martins Fontes: São Paulo, 2000, p. 178.

Statutes Of The International Red Cross And Red Crescent Movement. Adopted by the 25th International Conference of the Red Cross at Geneva in 1986, amended in 1995 and 2006.

SWINARSKI, Christophe. DIREITO INTERNACIONAL HUMANITÁRIO: Como sistema de proteção internacional da pessoa humana (Principais noções e institutos). São Paulo: Editora Revista dos Tribunais, Universidade de São Paulo, Núcleo de Estudos da Violência, 1990.

SWINARSKI, Christophe. 0 direito internacional humanitário como sistema de proteção internacional da pessoa humana. São Paulo, 2001

UNIC/Rio/005. Declaração Universal dos Direitos Humanos. Jan 2009. $\mathrm{DPI} / 876$.

UNHCR. Global Trends Forced Displacement in 2017. 2017.

UNHCR. International Federation of Red Cross and Red Crescent Societies. Disponível em: https://www.unhcr.org/international-federation-redcross-red-crescent-societies.html Acesso em: 18 ago 2019.

ParaOnde!?, Porto Alegre, v.13, n.2, p.105-121, 2020.http://seer.ufrgs.br/paraonde Edição Especial - VII Seminário Internacional de Estudos Fronteriços 
UN GENERAL ASSEMBLY. Statute of the Office of the United Nations High Commissioner for Refugees. 14 December 1950, A/RES/428(V). Disponível em: https://www.refworld.org/docid/3ae6b3628.html Acesso em: 06 jun 2019.

VATTEL, Emer de. $O$ direito das gentes. Prefácio e tradução: Vicente Marotta Rangel. Brasília: Editora Universidade de Brasília, Instituto de Pesquisa de Relações Internacionais, 2004. 